\title{
THE BIO-MORPHOLOGICAL FEATURES OF THE AROMATIC SPECIES Elsholtzia stauntonii Benth. UNDER THE CONDITIONS OF THE REPUBLIC OF MOLDOVA
}

\author{
Colţun Maricica, Cutcovschi-Muștuc Alina \\ National Botanical Garden (Institute) "Alexandru Ciubotaru” \\ e-mail:mcoltun@mail.ru
}

The research on new species of aromatic and medicinal plants and their introduction in the flora of other regions as industrial crops help extending the range of essential oils, which are main ingredients in fragrances and skin-care products, alcoholic beverages and soft drinks, as well as nontoxic pharmaceutical products. The use of new plant species opens up new ways to identify effective measures to promote health and prevent diseases naturally, to produce plant-derived medicines, which can cure some diseases and have a complex action on the body, stimulating its defense mechanism.

The species Elsholtzia stauntonii Benth., of the family Lamiaceae, is particularly interesting in this field. It was introduced in the NBGI in 2014 and has since been researched as an aromatic and medicinal plant. It is naturally common in China and Pakistan. The initial material was received by seed exchange from Hortus Botanicus Latvia. Under the conditions of R. Moldova, it grows as a perennial shrub, which typically reaches $60-90 \mathrm{~cm}$ in height, $60 \mathrm{~cm}$ in diameter and its shoots are about $65-70 \mathrm{~cm}$ long. The leaves are opposite, elongated-ovate, $9-12 \mathrm{~cm}$ long and $4-5 \mathrm{~cm}$ wide, they fall off at the end of the growing season, in november. The inflorescences are large spikes. The length of the central inflorescence is $4-17 \mathrm{~cm}$. There are more flowers in the lower spiral and less in the upper spiral. The flowers are about 6-9 $\mathrm{mm}$ long and 2.5-3.0 $\mathrm{mm}$ in diameter. The mass of $1000 \mathrm{seeds}$ is $0.2 \mathrm{~g}$.

The life cycle of a plant, in the first year, is complete, however, the onset of phenological stages is delayed and thus the fruits do not fully ripen. The plants grow the most rapidly in the second half of June and the beginning of July. At the end of august - beginning of september, inflorescences are formed in the upper part of the main and lateral buds. In the second and subsequent years, the growing season begins at the end of March. Up to 50 perennial shoots with a length of $35-70 \mathrm{~cm}$ develop, the most active growth is observed in May. The mass flowering stage begins at the end of July and lasts for 31-42 days. The plants are very beautiful at the time of flowering, when they are completely covered with spike inflorescences of purple flowers, at the ends of the branches. At the end of September, the fruit ripening stage starts. The growing season lasts for 125-145 days, depending on the weather conditions.

Elsholtzia stauntonii Benth. prefers sunny areas with light, fertile soils. It shouldn't be cultivated in areas where groundwater is close and in areas with heavy, clay soil. The shrub is shaped by pruning it yearly, which also helps improve the productivity of the plant. The load of the bushes must not exceed 35-40\% of shoots with a nutrition area of $80 \times 40 \mathrm{~cm}$. Plants can be pruned annually in the spring, starting with the second year after planting. Once every five years, the plant needs to be rejuvenated by cutting the shoots at a height of $15-20 \mathrm{~cm}$ from the surface of the soil. The biologically active substance is essential oil, the content of which increases before the flowering begins, reaching its peak in this phase and then begins to decrease. A similar picture was also observed in previous years. The maximum concentration of essential oil was found at the beginning of the flowering stage and constituted $0.5-1.65 \%$. According to literature data, the essential oil of the studied species has strong antibacterial activity, being effective against pathogenic bacteria. The dry matter contains a series of vital micro- and macronutrients: iron, manganese, molybdenum etc., which make it useful in the treatment of anemia, as a diuretic and stimulant for digestion, as well as in the treatment of diseases of the respiratory system. This plant has not yet revealed all its secrets. It is very promising for further study - there are great prospects for researchers and amateurs of new natural products. 